\title{
The provision of emergency contraceptives in private sector pharmacies in urban Kenya: Experiences of mystery clients
}

\author{
Francis Obare ${ }^{\#}$, Jill Keesbury"\# and Wilson Liambila" \\ \#Population Council, Nairobi, Kenya \\ \#Population Council, Lusaka, Zambia \\ fonyango@popcouncil.org
}

\begin{abstract}
This paper presents the results of an assessment of the provision of emergency contraceptives (EC) in private pharmacies in Nairobi, Kenya. Trained female mystery clients (MCs) made a total of 103 visits to 20 randomly selected pharmacies and presented accounts of their experiences. The results show that: I) some providers insist on doctors' prescriptions before they can dispense EC; 2) there are variations among providers on the recommended dosage and possible side-effects of EC pills; 3) MCs presenting as inexperienced clients were significantly more likely to be given additional information on EC than the experienced ones; 4) there was no significant difference in the provision of additional reproductive health $(R H)$ information/services by the scenario presented. This suggests the need for: I) provider training and/or updates on EC to enhance their capacity to offer additional RH information/services; 2) sensitizing EC clients on the importance of obtaining additional $\mathrm{RH}$ information/services from providers.
\end{abstract}

Keywords: Emergency contraceptives, Kenya, provision, private pharmacies, mystery clients

\section{Résume}

Ce document présente les résultats d'une évaluation sur l'offre des méthodes de contraception d'urgence (CU) dans les pharmacies privées de Nairobi, au Kenya. Les clients «mystères » formés avaient fait au total 103 visites au niveau de 20 pharmacies choisies au hasard et ont pu partager leurs expériences. Les résultats ont montré que: I) les prestataires de service exige une prescription médicale pour l'offre d'une CU; 2) les avis des prestataires de service différent quant à la posologie et aux effets secondaires éventuels liés à l'utilisation des pilules de CU; 3) les clients «mystères " présentés comme étant des clients inexpérimentés étaient plus susceptibles de recevoir des informations complémentaires sur la CU que celles qui en avaient l'expérience; 4) selon le scénario présenté, il n'y avait pas de différence majeure sur l'offre de l'information/services complémentaires liés à la santé de la reproduction. Cela implique le besoin de: I) former et faire des mises à jour sur la CU pour renforcer les capacités des prestataires de services dans l'offre d'informations /services complémentaires; 2) sensibiliser les clients sur l'importance d'obtenir de la part des prestataires de services des informations complémentaires sur la CU. 


\section{Introduction}

Over the past decade, emergency contraceptives (EC) have become increasingly available across Africa (Schiappacasse and Diaz, 2006). ${ }^{2}$ Although more government clinics than ever before are providing EC, in many countries private sector pharmacies remain the main channel through which clients obtain EC pills (Programme for Appropriate Technology in Health (PATH), 2004; Blanchard et al., 2005; United Kingdom Office of National Statistics, 2005; Moreau et al., 2006; Schiappacasse and Diaz, 2006). This is mainly because of the conveniences such outlets offer, namely, affordability, quick service delivery, and confidentiality. Owing to client preference, private pharmacies can play an important role in providing EC and possibly other reproductive health $(\mathrm{RH})$ information and services to clients (Wells et al., 1998; PATH, 2004). To begin with, the need for EC because of regular unprotected sex or method failure suggests the need for a new or more reliable method of family planning (FP). Moreover, clients who seek EC may also have exposed themselves to the risk of sexually transmitted infections (STIs), including HIV/AIDS in high prevalence settings, and are therefore candidates for voluntary counselling and testing (VCT) services. Thus, a client's decision to use EC can be seen as marking the beginning of a new set of $\mathrm{RH}$ needs.

It is, however, not clear whether private sector pharmacy providers have the capacity to offer the additional information and services to EC clients. First, from a public health perspective, private pharmacies lack the incentives to take up important steps in providing services to EC clients such as counselling or referrals for on-going contraception and STIs/HIV prevention, a concept referred to as bridging. This could be attributed to two factors, namely, the nature of training for pharmacists (which may not include the provision of public health information and services) and the fact that interactions with clients at pharmacies are mostly with frontline staff some of whom lack formal training in health service provision (PATH, 2004). Second, private pharmacy providers are often faced with the challenge of balancing operations as a business establishment and performing the role of health service providers (Skibiak et al., 200I; PATH, 2004).

Given these limitations and the fact that private sector pharmacies are the preferred sources of EC pills (Morgan, 2007; Keesbury et al., 2008), effectively enhancing the capacity of the providers to offer additional $\mathrm{RH}$ services to $\mathrm{EC}$ clients remains a challenge. One strategy which has been found to be effective is the provision of on-the-job training (PATH, 2004). Nonetheless, this strategy can, in the long-term, be unsustainable because of high rates of staff turnover and cost. In 2008, Population Council tested the feasibility of using a strategy that involved regular visits and updates to the providers at the facilities as a way of enhancing their capacity to offer counselling and referral for regular FP and other $\mathrm{RH}$ services to EC users. The study was conducted in Nairobi, Kenya, and involved the provision of information, education and communication (IEC) materials as well as regular updates on EC use and provision, including the need to 'bridge' 
users to regular FP and other STI/HIV services. This paper presents the results of the baseline assessment of the provision of EC in the private sector pharmacies as experienced by mystery clients.

\section{Methods}

\section{Baseline study design}

The first criterion for selecting the pharmacies to include in the study was that they already had contact with the Population Services International (PSI) social marketing programs. This meant that they were stocking and selling EC. PSI provided a list of the busiest pharmacies in Nairobi that were staffed by a pharmacologist, a pharmacist, or a pharmacy assistant. From a total of 98 pharmacies that satisfied this criterion, 20 were randomly selected for inclusion in the study. Time and financial constraints played a role in the decision to base the study on the 20 pharmacies. Twelve female research assistants were then recruited and trained to act as mystery clients (MCs) in need of EC pills. These were single women aged between 19 and 32 years, in line with findings from previous studies which show that the main users of EC fall within this age group (Shawe et al., 200 I; Olszewski et al., 2007).

The MCs were trained to present the providers with two scenarios which were developed with the help of a group of pharmacists from some of the outlets that were not selected for inclusion in the study. The first scenario was that of an inexperienced EC client who had had unprotected sex one or two days prior to the visit date, and was not sure if there was a method that she could use to avoid getting pregnant.
The second scenario was that of an experienced client who knew the product she wanted and went to the pharmacy to ask for it. The visits to pharmacies were arranged such that each pharmacy could only be visited by at most two different MCs each day to avoid saturating the pharmacies with visits. The MCs played alternating roles such that if the first visitor to a pharmacy in a particular day was an inexperienced client, the next would play the role of an experienced one. Nonetheless, the proportion of visits when the MCs presented as inexperienced EC users was more than when they presented as experienced users by the ratio of three to one (Table I) because: I) each day all MCs started by presenting as inexperienced clients; and 2) not all pharmacies were visited six times (the maximum number of visits to a pharmacy).

The MCs observed the provider's ability to respond to the need for EC as an FP method as well as to special needs within the broader RH context, including counselling and referral for regular FP and STI/HIV services. To reduce recall bias, the MCs were debriefed immediately following their pharmacy visits. They responded to a short questionnaire on whether: I) there were any IEC materials on EC at the pharmacy, 2) they were provided with EC pills and any information on the method, and 3) the provider talked to them about other FP methods as well as STIs and HIV. In addition to the questionnaire, the MCs provided qualitative accounts of their experiences at each pharmacy, first by narrating their experiences verbatim, then by recording the narratives in notebooks provided for 
the purpose. This paper presents findings from both the quantitative data and the qualitative accounts.

\section{Mystery client method and ethical issues}

The mystery client method entails using trained people to visit program facilities in the assumed role of real clients, and then report on their experience by completing a survey or through an interview (Boyce and Neal, 2006). The use of MCs helps to avoid bias in the service delivery process that can result from directly observing service transactions. In the case of EC provision, direct observation is likely to lead to even more serious bias as clients usually prefer fast and confidential delivery of service. Moreover, since MCs are used to assess and improve the quality of services, they serve the interests of clients, providers and programs by highlighting ways in which service provision could be enhanced (Boyce and Neal, 2006). However, the method has its disadvantages. For instance, service providers may consider it deceitful if they find out that they are not dealing with real clients. The MCs face potential physical or psychological harm when their real intentions are discovered, or when they are provided with services they do not need (Huntington and Schuler, 1993; Boyce and Neal, 2006).

To minimize the possibility of providers discovering the real intentions of the MCs, two-thirds of the training was devoted to role plays to ensure that the MCs were comfortable with their roles. They were also made to understand that under no circumstances were they to act in a manner that would raise suspicion on the part of the providers that they were not genuine clients. Further- more, the $M C$ visits were scheduled such that no client visited a pharmacy more than once. With respect to the potential risk of MCs being offered services they did not need, it was emphasized during training that they were not required to undergo any type of medical exam or procedure during their visits. The project also provided the MCs with money for purchasing EC from the pharmacies in the event that they were offered the pills. The purchased pills were then surrendered to the project during debriefing.

The project further obtained written consent to participate in the study from the selected pharmacies. The process involved explaining the study and its purpose, letting the pharmacists know that their facilities would be visited by MCs, explaining the potential risks and benefits of participating in the study, as well as emphasizing that participation was voluntary and that a facility could withdraw from the study any time. The providers were, however, not informed about the identities of the MCs or the exact dates when they would visit. Written consent was also obtained from the MCs on the first day of training after they were provided with the relevant information about the assignment, including the risks and benefits involved. Ethical clearance for the study was obtained from the Ethics Review Committee of the Kenya Medical Research Institute (KEMRI).

\section{Results}

The MCs made a total of 103 visits to the selected pharmacies over three days of baseline assessment of EC provision (Table I). Only one pharmacy was visited twice because, though the 
management had expressed willingness to allow the pharmacy to be included in the study, written consent was obtained on the second day of the assessment. The MCs presented the scenario of inexperienced clients in nearly threequarters of the visits, and were attended to by female service providers in more than half of the visits.

Table I: Percent distribution of mystey client visits to pharmacies by various background characteristics

\begin{tabular}{lcc}
\hline \multicolumn{1}{c}{ Characteristics } & Percent & $\begin{array}{c}\text { Number of visits } \\
(\mathbf{N})\end{array}$ \\
\hline Number of visits to a pharmacy & 2 & 2 \\
2 & 8 & 8 \\
4 & 44 & 45 \\
5 & 47 & 48 \\
6 & & \\
Scenario presented by mystery client & 27 & 28 \\
Experienced client & 73 & 75 \\
Inexperienced client & & \\
Sex of provider & 44 & 45 \\
Male & 56 & 58 \\
Female & & 13 \\
Position of provider & 13 & 22 \\
Pharmacist & 21 & 68 \\
Pharmacy assistant & 66 & \\
Could not tell & 100 & 13 \\
\hline Total & & \\
\hline Notes: Percentages may not add & (3) & \\
\hline
\end{tabular}

Notes: Percentages may not add up to exactly 100 in some cases because of rounding.

The MCs were provided with EC pills in about four-fifths of the visits to pharmacies (Table 2). Purchase statistics further show that Postinor-2 and ECEE2 were the only available brands: the former comprised $97 \%$ of the purchased products with the cost ranging from slightly more than one to two United States (US) dollars depending on the pharmacy. The main reasons for non-provision of EC were that: I) the pharmacists insisted on doctors' prescriptions before they could dispense $E C$, and 2) the pills were out of stock at the time of the visit. This is illustrated by the following excerpts from qualitative accounts:

I approached this lady at the 
counter, I couldn't tell her profession, and as I explained my situation, that I had sex and wanted some help to prevent unwanted pregnancy, she told me that they don't sell those drugs without a doctor's prescription. So there was no way she could help me. (MC No. RA06; Pharmacy No. WE23).

The man who attended to me didn't cooperate. After giving my story, he told me to go see a doctor who would give me a prescription. Then I take the prescription to him. (MC No. RAI0; Pharmacy No. WE I6)

I went to the chemist and found this man standing at the counter. I approached him and told him that I had unprotected sex last night and I have been advised by a friend that there are pills I could take to prevent conception. He told me to go and get all the information about EC before contemplating using the pills. I insisted that he tells me about the EC pills but he told me that they were out of stock because he had just sold the last packet. (MC No. RAI0; Pharmacy No. $\mathrm{KI} 77$ )

The lady attendant seemed to know about ECs ... On asking for P-2 [Postinor 2], the lady responded by saying that they had the medication but it got finished. But they would have them by the following day. (MC No. RA06; Pharmacy No. MA75)

Table 2: Percent distribution of mystery client visits by the type of reproductive health information/ services offered and by the scenario presented

\begin{tabular}{|c|c|c|c|c|c|}
\hline $\begin{array}{l}\text { Type of reproductive health } \\
\text { information/service offered }\end{array}$ & $\begin{array}{l}\text { Experienced } \\
\text { client (\%) }\end{array}$ & $\begin{array}{l}\text { Inexperien- } \\
\text { ced client } \\
(\%)\end{array}$ & $\begin{array}{l}\text { Chi- } \\
\text { square } \\
\text { test }\end{array}$ & $\begin{array}{c}\text { All } \\
\text { visits } \\
(\%)\end{array}$ & $\begin{array}{c}\text { Number } \\
\text { of visits } \\
\text { (N) }\end{array}$ \\
\hline Mystery client provided with EC & 82 & 81 & ns & 82 & 103 \\
\hline $\begin{array}{l}\text { Mystery client offered additional } \\
\text { information on EC }\end{array}$ & 25 & 69 & **⿻丷木 & 57 & 103 \\
\hline \multicolumn{6}{|l|}{$\begin{array}{l}\text { Additional EC information } \\
\text { provided }^{\mathrm{a}}\end{array}$} \\
\hline $\begin{array}{l}\text { When to use EC (time } \\
\text { frame) }\end{array}$ & 57 & 60 & ns & 59 & 59 \\
\hline How to use EC (dosage) & 71 & 83 & ns & 81 & 59 \\
\hline $\begin{array}{l}\text { Advantages of using EC } \\
\text { (what EC does) }\end{array}$ & 29 & 12 & ns & 14 & 59 \\
\hline $\begin{array}{l}\text { Side-effects of EC (disad- } \\
\text { vantages) }\end{array}$ & 57 & 46 & ns & 47 & 59 \\
\hline $\begin{array}{l}\text { Efficacy (how effective EC } \\
\text { is) }\end{array}$ & 43 & 42 & ns & 42 & 59 \\
\hline Other & 14 & 6 & ns & 7 & 59 \\
\hline
\end{tabular}


Provider gave/talked about other FP methods

Type of other FP service offered ${ }^{\mathrm{a}}$

Given regular FP method

Recommended regular FP

Referred to clinic/hospital for FP

Other

Provider talked about HIV/AIDS and other STIs

Type of HIV/AIDS/STI service offered $^{\mathrm{a}}$

Recommended abstinence

Referred to VCT centre

Referred to clinic/hospital

Other
18

21

21 ns

20

103

the

$\begin{array}{ccccc}0 & 6 & \text { ns } & 5 & 21 \\ 80 & 69 & \text { ns } & 71 & 21 \\ 20 & 38 & \text { ns } & 33 & 21 \\ 20 & 13 & \text { ns } & 14 & 21 \\ 14 & 15 & \text { ns } & 15 & 103\end{array}$

103




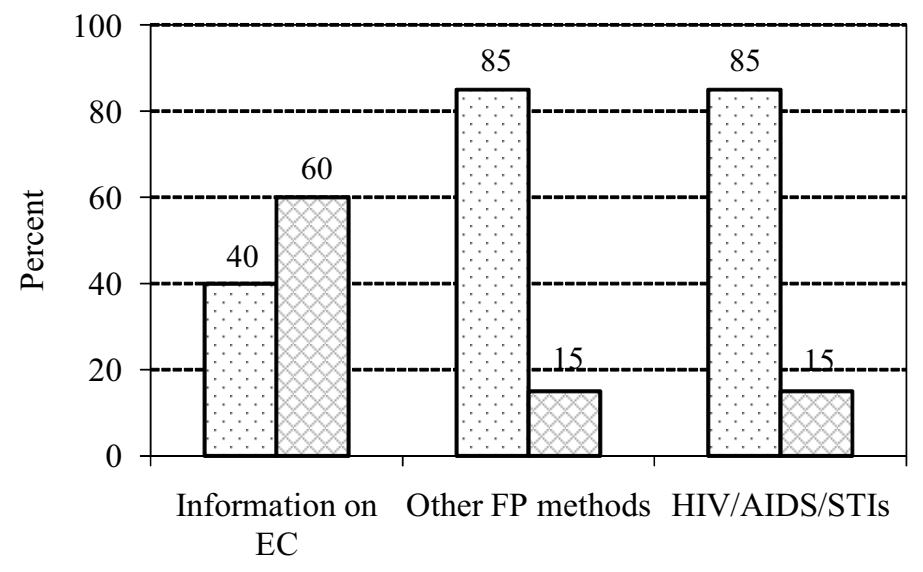

$\square$ Less than half $\square$ One-half or more

Figure I: Percent distribution of pharmacies by the proportion of client visits during which additional reproductive health information/service was provided.

Notes: EC- emergency contraceptives; FP- family planning; STIs- sexually transmitted infections.

As I was packing the pill in my bag, I decided to ask him how to use it and he said that I should take one right then and the other after 6 hours or, I could take two of them at once. (MC No. RA09; Pharmacy No. MA75)

The attendant told me to take both pills at the same time, because to her, they would be more effective ... When I told her that 48 hours had elapsed, she was afraid and told me to take both pills at once. (MC No. RAI2; Pharmacy No. CE29)

The woman explained to me that it is very effective if used within the first twelve hours but as I had told her I had sex two days ago, she told me that it might not be very effective, especially if my fertility rate is high. She told me for it to be effective, I take two immediately. (MC No. RA05; Pharmacy No. KI76)

Qualitative data indicate that most providers who offered additional information on EC mentioned the 72-hour window within which the pills are effective. In addition, whereas some providers recommended taking one tablet twelve hours apart, others recommended a shorter time between doses while others told the clients to take the two tablets at once. Furthermore, most providers who mentioned side-effects identified nausea and vomiting as the most common ones with some mentioning hormonal imbalance, ectopic pregnancy, infertility, body resistance, and irregular monthly periods as other side-effects. In some instances, the pro- 
viders simply referred the MCs to the inserts in the EC packets for more information as illustrated by the following accounts:

She didn't have much information about the side effects when I asked her but referred me to read the paper inside the packet. (MC No. RAOI; Pharmacy No. CE55)

He told me to take one and the other one after 12 hours and also to make sure I read and follow the instructions in the leaflet as he quickly left to serve another client. (MC No. RA09; Pharmacy No. CE29)

The attendant at first denied me any assistance because I didn't know the type of pill that was good for me and my body. Later, he accepted to give me the EC pills and he advised me to read the instructions from the attached leaflet. (MC No. RAI I; Pharmacy No. KI77)

The likelihood of clients being offered additional information on EC was significantly higher when they presented as inexperienced rather than as experienced users of EC (Table 2). However, there was no significant difference in the proportion of $M C$ visits when the providers talked about other FP methods or HIV/AIDS/STIs by the scenario presented. Providers who talked about other FP methods mostly recommended a regular method while those who talked about HIV/AIDS/STIs more often recommended condoms or referred the clients to a health centre.

\section{Discussion and implications}

One of the key experiences of mystery clients in the study is the insistence by some pharmacists on doctors' prescriptions before they could dispense EC. This is in contrast to the 2005 Ministry of Health $(\mathrm{MOH}) /$ Department of Reproductive Health (DRH) guidelines for family planning service provision in Kenya. With respect to EC, the guidelines stipulate that the pills can be provided by all trained service providers, and in any facility with a qualified provider (MOH/DRH, 2005). The requirement for a prescription from a doctor has both time and financial implications for potential EC users, especially those who need it because they engaged in consensual unprotected sex. The time required to secure a doctor's appointment and for consultation beats the logic of EC being used for emergency cases while the doctor's consultation fee adds additional cost to the user. This could have a double-sided effect on EC use: on the one hand, doctors might be in a better position to provide adequate information to potential clients than pharmacists; on the other hand, it could limit access by those who genuinely need the method but are unable to raise the doctor's fees.

The second important experience of MCs is the variation among providers on how and when to use EC pills. Most providers were aware of the 72-hour window of opportunity during which EC pills can help prevent unwanted pregnancy after unprotected sex. However, recent guidelines indicate that EC pills can be effective for up to I 20 hours (International Consortium for Emergency Contraception (ICEC), 2004; $\mathrm{MOH} / \mathrm{DRH}, 2005)$. This discrepancy 
could largely be a result of what seems to be confusion in the field rather than the ignorance of the providers: whereas the 120-hour guideline has been around for some time, product inserts still indicate 72 hours. The variations in recommended dosage and side-effects among providers, however, point to the need for provider training and/or updates on EC use and provision. This might seem to contradict the earlier contention that provider training might not be sustainable in the long term due to the high rate of staff turnover at private pharmacies. Nonetheless, EC use and provision could be included in the curriculum used for pre-service training for health service providers, including pharmacists. A study in Bangladesh, for instance, showed that this is an effective strategy for encouraging bridging (Hossain, 2008). The finding that the MCs were more likely to be offered additional information on EC than to receive additional information on other FP methods and HIV/AIDS/STIs underscores the need for provider training and/or updates on bridging.

Finally, differences in the likelihood of being offered additional information on EC by the scenario presented by the MCs suggest that interventions should not just focus on providers but also on clients. Clients need to be sensitized on the need to obtain additional information on EC and other RH services from the providers. However, one of the challenges could be how to handle experienced clients who feel that they know what they need and are for quick service. A possible way around this could be to include a simple message or informational insert in the EC packet to inform users about other $\mathrm{RH}$ services.
This, however, requires coordination with EC manufacturers; its feasibility is therefore subject for further research.

Notes

I. The pharmacy study was implemented by the Population Council in collaboration with Population Services International (PSI) through funding from the William and Flora Hewlett Foundation. The Kenya Medical Research Institute (KEMRI) provided ethical clearance for the study. We also acknowledge the team of research assistants who acted as mystery clients and the proprietors of pharmacies who provided consent for their outlets to be included in the study. The views expressed in this paper are, however, those of the authors.

2. EC or the 'morning after' pills refer to methods used to prevent pregnancy after unprotected sexual intercourse. The pills are effective for up to five days ( 120 hours) after unprotected sex, but the sooner they are taken, the better they work. EC pills prevent pregnancy through inhibiting or delaying ovulation, thereby preventing fertilization and implantation. The pills are not effective once a woman is pregnant - they neither interrupt an existing pregnancy nor cause abortion.

\section{References}

Blanchard, K., Harrison, T. and Sello, M. 2005. 'Pharmacists' knowledge and perceptions of emergency contraceptive pills in Soweto and the Johannesburg Central Business District, South Africa." International Family Planning Perspectives 3I, (4): 
I72-I 78.

Boyce, C. and Neale, P. 2006. Using Mystery Clients: A Guide to Using Mystery Clients for Evaluation Input. Watertown, MA: Pathfinder International.

Hossain, S.M.I. 2008. "EC opens the window for other $\mathrm{RH}$ services in Bangladesh." In F. Onyango, J. Keesbury, and Y. Faye (eds.). 'EC as a 'bridge'.' ECafrique Bulletin 5, (I): 7.

Huntington, D. and Schuler, R.S. 1993.

"The Simulated Client Methodology: Evaluating Client-Provider Interactions in Family Planning Clinics." Studies in Family Planning 24, (3): 187-193.

International Consortium for Emergency Contraception (ICEC). 2004. Emergency Contraceptive Pills: Medical and Service Delivery Guidelines. Washington, DC: ICEC.

Keesbury, J., Morgan, G., and Owino, B. "Who uses emergency contraception in Kenyan pharmacies?" Population Council: ECafrique Working Paper, 2008.

Ministry of Health (MOH)/Department of Reproductive Health (DRH) [Kenya]. 2005. Family Planning Guidelines for Service Providers. Nairobi: $\mathrm{MOH} / \mathrm{DRH}$.

Moreau, C., Bajos, N. and Trussell, J. 2006. "The impact of pharmacy access to emergency contraceptive pills in France." Contraception 73:602-608.

Morgan, G. 2007. "Private Sector EC Use: A Profile of EC Users." Paper presented for: Kenya Ministry of
Health EC Data Interpretation Workshop. Nairobi. 28 August.

Olszewski, J., Olszewska, H., Abacjew, A., Chmylko, L. and GaworskaKrzeminska, A. 2007. "The use of emergency contraception in young Polish women." Acta Obstetricia et Gynecologica 86: 86I-869.

Program for Appropriate Technology in Health (PATH). 2004. "Increasing access to reproductive health services through pharmacists" Outlook 2 I (2). Seattle: PATH.

Schiappacasse, V. and Diaz, S. 2006. "Access to emergency contraception." International Journal of Gynecology and Obstetrics 94: 30I 309.

Shawe, J., Ineichen, B., and Lawrenson, R. 200I. "Emergency contraception: Who are the users?" The Journal of Family Planning and Reproductive Health Care 27, (4):209-2I 2.

Skibiak, J.P., Moyo, M.C., and Ahmed, Y. 200I. Testing alternative channels for providing emergency contraception to young women. Nairobi: Population Council.

United Kingdom Office of National Statistics. 2005. "Greater use of pharmacies to access 'morning after pill'." Contraception and Sexual Health, Series OS No.28.

Wells, E.S., Hutchings, J., Gardner, J.S., Winkler, J.L., Fuller, T.S., Downing, D. and Shafer, R. 1998. "Using Pharmacies in Washington State to Expand Access to Emergency Contraception." Family Planning Perspectives 30, (6): 288-29. 